\title{
JOSÉ DONOSO: CASA DE CAMPO
}

ALFRED J. MAC ADAM

University of Virginia

En 1844, en París, Marx y Engels escribieron uno de sus libros más polémicos y más divertidos: La sagrada familia, o crítica a la crítica crítica: contra Bruno Bauer y compañia. ${ }^{1}$ En él desarrollan algunas ideas de Pierre Joseph Proudhon y dicen lo siguiente sobre el concepto de la "propiedad privada":

El proletariado y la riqueza son opuestos; como tal forman una sola totalidad. Los dos son formas del mundo de la propiedad privada. La cuestión es el lugar que cada uno debe ocupar en la antítesis. No basta con declararlos dos partes de una misma totalidad. La propiedad privada, como propiedad privada, como riqueza, está obligada a mantenerse a sí misma, y, como consecuencia, a mantener a su opuesto, el proletariado, en existencia. Este es el lado positivo de la contradicción, la propiedad privada ufana... El proletariado, en cambio, está obligado, como proletariado, a abolirse a sí mismo y, por consiguiente, a su opuesto, la condición de su existencia, lo que lo hace el proletariado, i.e. la propiedad privada. (p. 37)

Marx y Engels analizan el mundo creado por la propiedad privada, el mundo que resulta de la presencia en la realidad de este concepto, por medio de oposiciones: el proletariado es el opuesto de la riqueza, y los dos resultan del hecho de que el mundo ha aceptado la propiedad privada como una donnée. La propiedad privada, como si fuera un ser vivo, se esfuerza por subsistir y sólo puede subsistir si el proletariado también subsiste. El proletariado, en cambio, no debe y no quiere persistir como tal, pero para cambiar su situación enajenada tiene que dejar de existir junto con su opuesto, la propiedad privada. Los propietarios necesitan a los que nada tienen, mientras que los que no poseen nada tienen que desaparecer para que los que deforman su existencia desaparezcan también. Y así lo dicen Marx y Engels:

\footnotetext{
' Karl Marx y Friedrich Engels, Die heilige Familie, oder Kritik der Kritischen Kritik: gegen Bruno Bauer und Konsorten, en Werke, Band 2 (Berlin: Dietz Verlag, 1962). Todas las citas son de esta edición. Las traducciones son mías.
} 
Cuando el proletariado alcance la victoria, no se transformará en el único lado de la sociedad, porque será victorioso sólo cuando se anule a sí mismo y a su opuesto. Entonces desaparecerá el proletariado igual que el opuesto que lo ha determinado, la propiedad privada... Pero el proletariado no puede liberarse sin abolir las condiciones de su vida. No puede abolir las condiciones de su vida sin abolir todas las condiciones inhumanas de la vida de la sociedad de hoy, condiciones que se encuentran todas en la situación del proletariado. (pp.37-38)

Estas observaciones nos llevan a pensar en el poder del concepto de la propiedad privada, el robo según la famosa definición de Proudhon. Esta abstracción, que Marx y Engels quieren revelar como una ficción y no un hecho real, es el concepto formativo de Casa de campo, de José Donoso. ${ }^{2}$

La designación "concepto formativo" no es una tentativa de subordinar el hecho estético (el texto) a uno de sus elementos (una idea derivada de la economía política) sino una afirmación de la importancia de esta idea, que puede orientar una lectura del texto. Habría que notar que la idea de la propiedad privada recurre en la obra de Donoso y que es el referente de una de sus metáforas más obsesivas, la del paquete (con sus variantes: el ataúd, el cuerpo humano, la ropa, el libro, la casa). Es decir, una de las grandes preocupaciones de la obra de Donoso es nuestra edad de hierro en que las palabras "mío" y "tuyo" no sólo nos diferencian de aquellos que vivían sin propiedad privada sino que también subrayan el hecho de que el acto de poseer da una identidad al dueño. Poseer algo es ser alguien; no poseer nada es no ser nadie.

Casa de campo es un momento en la larga historia de una familia de propietarios, los Ventura, momento en que su concepto de la historiarepetición ritual, posesión perpetua de las mismas riquezas y del mismo poder-sufre una alteración. Esta alteración se relaciona con el análisis de la idea de propiedad que vemos en Proudhon, Marx y Engels: lo que los Ventura toman como hechos, como realidades, son ficciones. Como dicen Marx y Engels:

Los terratenientes y el proletariado presentan la misma auto-enajenación humana. Pero los terratenientes encuentran en esta auto-enajenación su confirmación y su bien, su poder: en ella tienen una apariencia de existencia humana. El proletariad o se siente anonadado en su auto-anajenación; en ella ve su propia impotencia y la realidad de una existencia inhumana. (p. 37)

La riqueza de los Ventura, su razón de ser, se basa en el oro (eco irónico de la edad de oro descrit o por Don Quijote en su discurso a los cabreros) que los nativos, que viven cerca de la casa de campo del título, minan y transforman en láminas. Empaquetadas las láminas en fardos, los nativos las entregan a los

\footnotetext{
${ }^{2}$ Casa de campo (Barcelona: Editorial Seix Barral, 1978). Todas las citas son de esta edición.
} 
Ventura a trueque de productos que los nativos no pueden producir en su comunidad. Los Ventura, que se apoderaron de las minas y los nativos en un pasado remoto y guerrero, venden las láminas a extranjeros y en esta venta transforman el oro en dinero, concepto desconocido por los nativos. Este sistema, el colonialismo más puro, ha durado siglos porque los Ventura han definido a los nativos como antropófagos. Un antropófago, según la ideología de la Conquista, no puede ser un hombre porque los hombres no comen a los hombres; ergo, los antropógafos no son seres humanos y es lícito escla vizarlos. Una ficción, la propiedad privada y la necesidad de conservarla, engendra otra--los nativos por ser caníbales merecen ser esclavos-y así los Ventura construyen una moralidad y una justificación. La historia y la tradición apoyan estas costumbres: cualquier cambio sería inmoral.

La propiedad privada engendra entonces un orden, una estructura social: los Ventura son el ápice y los nativos la base. Pero hay también clases intermedias: los criados de la familia, superiores a los nativos pero carentes de identidad personal para los Ventura, los cuñados, necesarios para la existencia de la familia pero no precisamente iguales a los Ventura, y los hijos Venturas in potentia. La posible destrucción del mundo de los Ventura se encuentra precisamente en estos dos últimos grupos, los cuñados y los hijos, porque son los que más contacto tienen con el mundo externo. Los criados representan para los Ventura una amenaza de otra índole; como criados o como un sistema de espías (utilizado para vigilar a los hijos) no constituyen un peligro, pero armados e imbuidos con un sentido de misión-con lo que uno de los Ventura llama "la mística que ha guiado a nuestra familia desde siempre"(p. 269)--pueden llegar a serlo. La plena identificación de los criados con los valores de los Ventura les da algo que no tenían antes-una identidad-y en el momento en que se sienten poseedores de esta identidad, los Ventura llegan a ser prescindibles.

Sería posible leer Casa de campo como una alegoría sobre la historia reciente de Chile: la decisión de los Ventura adultos de hacer una excursiónde ausentarse voluntariamente del escenario-y dejar la casa de campo en manos de los hijos (la excursión debe durar sólo un día, pero ese día mágicamente se transforma en un año) puede corresponder a elecciones libres; el cuñado supuestamente loco, Adriano Gomara, que aparece como líder porque tiene buenas relaciones con los nativos y con los niños, puede corresponder a Salvador Allende; los criados galvanizados por los Ventura adultos para protejer sus derechos tradicionales significarían los militares que derribaron el régimen de Allende. El fracaso del gobierno de Adriano Gomara, su incapacidad de controlar totalmente a los más radicales, correspondería a las luchas intestinas que dominaron el gobierno de Allende. Todo esto es posible, pero no es de ninguna manera la única lectura posible del texto. 
Como El lugar sin límites (1966), Casa de campo puede leerse como una sátira irónica cuya estructura es la de una tragedia: empezamos en un mundo ordenado, el mundo de los Ventura; luego entramos en una fase de desorden, los Ventura se ausentan y un sistema nuevo trata de reemplazarlos; finalmente vuelven los Ventura o sus representantes armados, los criados, y el antiguo orden se reestablece. En la tragedia clásica y los mitos de que se derivan las tragedias, la sociedad amenazada por la destrucción, el orden amenazado por el desorden, se salva por medio de un sacrificio. Como observa René Girard, "La sociedad trata de desviar hacia una víctima relativamente indiferente, una víctima 'sacrificable,' una violencia que posiblemente destruirá a sus propios miembros, a aquellos que la sociedad tiene intención de proteger a toda costa". ${ }^{3}$ La sociedad puede escoger como víctima al extranjero, al deformado, al diferente-como Edipo en Tebas o como Manuel González Astica, la Manuela, en El lugar sin límites. La ironía entra en la configuración trágica precisamente en el momento en que nos damos cuenta de que el sacrificio sirve para perpetuar un orden negativo, un orden infernal como es el orden de don Alejand ro Cruz.

En Casa de campo tenemos la misma estructura pero con una diferencia: mientras que en El lugar sin límites tenemos la sensación de que el orden de Alejandro Cruz va a durar mucho más, a pesar de la vejez y la debilidad de don Alejandro, en Casa de campo tenemos la sensación de que los que han sobrevivido el golpe de los Ventura cuando toman de nuevo el poder serán los fundadores de una sociedad nueva. Los Ventura, en cambio, han ganado la batalla pero perderán la guerra precisamente porque no pueden trabajar como una comunidad. La propiedad privada que quieren conservar los aísla y hace que cada uno trate de robar lo que tiene el otro. Su sociedad es una pesadilla hobbesiana y parece derivada del infierno de Dante, donde los traidores en los cuatro círculos más bajos (Ugolino en particular) son antropófagos, siendo la antropofagia la inversión total de la comunión. Es decir, los Ventura usaban la designación "antropófago" para controlar a los nativos, pero los únicos antropófagos del texto son los mismos Ventura, prontos a robar unos de otros la sustancia que les da identidad-la propiedad privada.

El concepto de propiedad privada, tal como lo hemos enfocado en Casa de campo hasta aquí, puede parecer exclusivamente un aspecto de la obra como denuncia social, como crítica de la sociedad. Pero no es así, porque el concepto se extiende hasta la relación entre el autor y su texto. En Casa de campo, la voz narrativa que sirve de portavoz al autor, la voz que constantemente se refiere al texto como novela o fábula, se parece a la de

\footnotetext{
${ }^{3}$ René Girard, "Le sacrifice", La violence et le sacré (Paris: Bernard Grasset, 1972), p. 17. La traducción es mía.
} 
Thackeray al final de Vanity Fair: los personajes no son más que sus títeres y al final de la obra el autor los devuelve a sus cajas. En un momento, Donoso explica al lector sus intenciones, momento en que trata de aclarar la naturaleza de uno de los personajes principales, el niño Wenceslao:

Es que Wenceslao, igual que mis demás niños, es un personaje emblemático. Uno, quizás el más memorable, del grupo de niños y niñas que, como en un cuadro de Poussin, juguetean en el primer plano, inidentificables con ningún modelo porque no son retratos, porque sus rostros no están constreñidos por los estigmas de la individualidad y de las pasiones fuera de las más formales. Ellos y sus juegos son poco más que un pretexto para que el cuadro pueda llevar un nombre, porque lo expresado no reside tanto en sus juegos clásicos que sólo sirven como punto focal: tiene mayor jerarquía dentro de la tentativa del artista la interacción entre estos personajes y el paisaje de rocas y valles y árboles que se prolonga hasta el horizonte, de donde, en proporción áurea, despega del cielo, bellísimo, emocionante, intangible, que crea ese espacio aceptadamente, irreal que es el protagonista del cuadro, como la narración pura es protagonista en una novela que logra triturar personajes, tiempo, espacio, psicología y sociología en una sola marea de lenguaje. (pp. 372-373)

A diferencia de Donoso o su narrador, se puede afirmar que la "primera causa" del autor, su "intención" al escribir, es algo que siempre queda como un misterio para el lector. Este utiliza el texto para inventar técnicas que explican el texto según una u otra teoría de la literatura. La cuestión que surge aquí es si el autor mismo sabe cuáles son sus "intenciones" cuando escribe y hasta qué punto la intención explica a todos los elementos del texto. En el pasaje citado, Donoso alude a Poussin, pintor de cuadros cuyo contenido temático o melodramático es mínimo. Paisajes pastoriles, algunos pastores para señalar distancias o proporciones: cuadros donde el verdadero asunto es la pintura como juego de colores, como contraste de formas. Pero notamos en la descripción del cuadro hipotético de Poussin que, aunque el nivel literal del cuadro-la escena pastoril-queda subordinado a "la interacción entre... personajes y... paisaje", ésta sigue allí para darnos acceso al cuadro. (Por otra parte, no se trata de disminuir el poder intelectual de un cuadro como "Et in Arcadia ego" sino de señalar que aparte del drama que puede tener lugar entre los personajes de Poussin, hay el resto del cuadro que, en términos de espacio, es, muchas veces, más importante).

La "marea de lenguaje" que menciona Donoso al final del pasaje citado, una escritura que sería el lenguaje desligado de anécdota, existe sólo como teoría porque el lenguaje, medio de comunicación después de todo, resiste el acto de vaciarlo de significado. Es decir, el hecho de que el autor se siente obligado a proveer al lector un acceso (por mínimo que sea) a su texto señala que el texto no puede ser su propiedad privada. El artista, por hermético que 
sea, quiere tener a sus cómplices (para evocar a Cortázar) y este deseo nos recuerda que el acto de leer es un acto de comunión, aunque lo realizamos en la soledad. Donoso se ha insertado en el texto-no como Dante, que lo hace para aumentar el realismo de su narrativa, o Thackeray, que lo hace para subrayar la artificialidad de su novela-para mantener al lector a cierta distancia, para conservar algo del texto de manera que el lector no lo devore todo:

Al interponerme de vez en cuando en el relato sólo deseo recordarle al lector su distancia con el material de esta novela, que quiero conservar como objeto mío, mostrado, exhibido, nunca entregado para que el lector confunda su propia experiencia con él... La síntesis efectuada al leer esta novela-aludo al área donde permito que se unifiquen las imaginaciones del lector y del escritor-no debe ser la simulación de un área real, sino que debe efectuarse en un área en que la apariencia de lo real sea constantemente aceptada como apariencia, con una autoridad propia muy distinta a la de la novela que aspira a crear, por medio de la verosimilitud, otra realidad, homóloga pero siempre accesible como realidad. (pp. 53-54)

Claro, habría que preguntar aquí hasta qué punto se extiende el control del autor sobre el texto después de publicarlo porque es entonces, precisamente, cuando la propiedad privada se convierte en propiedad común. Aquí el autor-en-el-texto se engaña, y habría que recordarle dos antecedentes que también querían controlar su texto después de publicarlo, Víctor Frankenstein y Humberto Peñaloza. El texto en el mundo es de todos y de nadie, a diferencia de la casa de campo dentro del texto que sigue perteneciendo a los Ventura.

Aquella casa, al principio de la obra, está rodeada de una reja hecha de lanzas de hierro. Esta reja simboliza la propiedad privada de los Ventura y el hecho de estar ellos encerrados en ella. Visto desde afuera, el mundo de la casa de campo es como el mundo pastoril de los cuadros de Poussin. El primer acto de los niños y los nativos cuando se van los adultos es de derribar la reja; este trabajo en común destruye el concepto de propiedad privada y para los Ventura combina pecado y crimen. Pero al mismo tiempo este acto crea una tensión nunca resuelta con el deseo expresado por el autor-en-el-texto. Casa de campo describe el mundo infernal creado por la propiedad privada, entonces ¿qué hacer con el autor que quiere conservar el texto "como objeto mío, mostrado, exhibido, nunca entregado para que el lector confunda su propia experiencia con él'"? Se puede entender este deseo si se lo considera como una tentativa utópica-el mundo del texto no existe y así el lector no debe tomarlo como una realidad - pero al mismo tiempo parece haber aquí un elemento romántico, un deseo de no dejar que el texto sea lo único del autor que tenga contacto con el lector, un deseo de mantener un contacto directo entre el autor y el lector. 
Una manera de resolver este dilema sería insistir en que la voz del autor aquí no es más que otra voz narrativa, una que tiene la función de romper el mundo cerrado de la ficción para señalar su artificialidad-como la intervención de Thackeray en Vanity Fair. Es decir, ningún elemento del texto puede considerarse independiente del texto; no hay meta-texto sino texto. La problemática relación entre el creador y el texto publicado tal vez no tenga solución desde el punto de vista del lector: por más que el autor hable con su propia voz en el libro, nunca será más que otro personaje. Otra derrota para la propiedad privada. Por lo tanto, como los Ventura en situaciones desagradables, tendremos que "correr un tupido velo sobre este asunto". 
